\title{
'The smell of the place': Managerialist culture in contemporary UK business schools
}

Glaudo De Vita, Oxford Brookes University

Peter Case, University of the West of England \& James Cook University

By introducing an intentionally provocative critique of managerialist regimes which typify contemporary UK business school culture, we argue that current business school management practices generate a climate of mistrust and alienation amongst academics. Such a climate is not conducive to a reformative agenda that business schools should be pursuing if they are to improve staff morale and the educational environment. Drawing on Ghoshal's 'smell of the place' metaphor to structure this argument, we court deliberate irony and paradox. Rather than draw on heterodox theory to inform our critique we, instead, turn relatively mainstream management and organization theory against itself. Our argument is that even when examined through orthodox lenses, managerialist practices are found wanting and contradict the precepts of much mainstream normative theory.

Keywords: business schools; culture; Ghoshal; higher education; managerialism; metaphor;

\section{Introduction}


Intellectual debate about the increasing alienation of the UK academic community in contemporary 'Austerity Britain' has been scant. Of course, the literature has offered some polemical arguments regarding organizational leadership, management learning and education but - with few notable exceptions (see, for example, Butler and Spoelstra 2012 and 2014; Clarke, Knights and Jarvis 2012; Parker 2014) - there has been insufficient academic discussion of the unique circumstances currently being faced in the UK business school sector. Whilst Willmott (1994) and Grey and Mitev (2004), offered robust critiques of management studies curricula and pedagogical processes, little seems to have changed as a result of their perspicuous words.

Our focus here is not so much on curriculum and pedagogy, although these are both indirectly implicated; rather, we offer a snapshot of the 'culture' of contemporary UK business schools. We do so by courting deliberate irony and paradox. Rather than draw on heterodox theory to examine the culture and context of UK business schools and inform our critique we, instead, adopt an established framework (Ghoshal's springtime theory) in order to turn mainstream management and organization theory against itself. Our argument is that even when examined through orthodox lenses, managerialist practices are found wanting and contradict the precepts of mainstream normative theory. Highlighting a managerialist climate of increasing bureaucracy, constraints, compliance, and hyper-control in business schools, we contend that this culture runs counter to the prescriptions of much contemporary management thinking.

There is, doubtless, a cathartic dimension to our endeavor, but we suspect that, for some readers at least, the critique we offer may strike a resonant chord that facilitates collective catharsis; and, as the philosopher and social theorist Kenneth Burke (1969) 
pointed out, vicarious atonement is an important condition of any collective attempt to change extant social conditions. If business schools are to become 'better places' in which to work - where new generations of students and managers can be educated in responsible ways - then it is imperative that the status quo is challenged and creatively transformed.

Given the complexity of the conditions that have led to the current state of affairs, within the confines of a journal article we have by necessity to be selective in our treatment of issues. Before we outline the structure of the paper, however, it may be helpful to provide some background context within which the cultures of UK business schools are situated. As Radice (2013) and Collini (2013) have both pointed out, the UK university sector has been transformed by a set of interrelated forces attributable to the contemporary neoliberal ethos of capitalism (Harvey 2005). The four key changes that Radice notes are: (1) privatization of public assets; (2) deregulation of markets; (3) the dominance of financial controls; and, (4) globalization. Universities have not only been implicated within, or subjected to, this mix of forces, they have also played a role in their promulgation. The corollary of this development is threefold, according to Radice.

Firstly, the public purpose of universities has changed from the generation and dissemination of knowledge to one of enhancing the international competitiveness of UK plc. Teaching, research and capital resources are increasingly mobilized to produce productive labor that services the needs of the neoliberal political economy and it is the exchange-value of knowledge that is privileged over knowledge-for-knowledge's sake (see also Lyotard 1984). Secondly, the administration of universities is no longer driven collegiately by discipline-based academics but is, rather, increasingly centralized and shaped by a cadre of professional managers pursuing such bureaucratic imperatives as the 
'financialization' of academic work (see also McGettigan 2013) and performance management of staff using individualized incentives and punishments based on private sector models. Interestingly, Radice (2008) makes a compelling yet deeply ironic comparison between these trends and the Soviet system of state control. Thirdly, the culture of universities has accommodated these neoliberal transformations eschewing the notion of collective endeavor in favor of a fiercely competitive, dog-eat-dog, worldview. University cultures reflect an overarching homogeneous ideology in which quantitative targets, competition for jobs and places, and league tables are privileged over cooperative enquiry and academic inquisitiveness. In this milieu, of course, students become customers seeking to obtain credentials, and tutors become suppliers of useful knowledge (in a narrow utilitarian sense). As Collini $(2013,12)$ notes: 'The true use-value of scholarly labour can seem to have been squeezed out; only the exchange-value of the commodities produced, as measured by metrics, remains'.

Against this backcloth, Raunig (2013) argues that what was once the factory is now the university. With the incessant spreading of deindustrialization and an increasingly decentralized working class, new expressions of social resistance and political activism need to emerge in what may be the last places where they are possible: the university and the art world. Raunig (2013) calls for a reassessment of the importance of cultural and knowledge production by reaffirming the potential that cognitive and creative labor has in these two milieux to resist the new regime of domination imposed by cognitive capitalism. Framed within this context, he asserts, the central role of the university is not as a factory of knowledge but as a place of creative disobedience. 
The new 'regime of excellence' of the encroaching ideology of cognitive neoliberal capitalism that is now prevalent in the contemporary university - as manifested, for example, in journal rankings, research assessments and the diktats of managing editors of premiere outlets - has already been found to have an impact on cultural and knowledge production (see Butler and Spoelstra 2014); as exemplified by its influence on scholarship, decisions on what to research and where to publish, and the erosion of the ethos of critical scholars (ibid). This suggests that even critical management studies scholars, in a perverse twist of faith, 'may find themselves inadvertently aiding and abetting the rise of managerialism in the university sector, which raises troubling questions about the future of critical scholarship in the business school' (Butler and Spoelstra 2014, 538).

Although we are sympathetic to the radical lines of political economic critique offered by Radice, Collini, Raunig and others, we pursue an alternative line of argument. Our critique is intended to make the paradoxical yet fundamental point that, even when evaluated in terms of relatively mainstream management principles, business school management practices and the cultures they inculcate are counterproductive.

The paper is set out as follows. First, we introduce Ghoshal's 'springtime theory' and the associated 'smell of the place' metaphor from which we draw to articulate our critique of the consequences of the managerialist approach for UK business school culture. After having clarified the theoretical and methodological rationale alongside the boundaries of the objection we raise with respect to managerialism, we offer a discussion of how the organizational climate within many UK business schools resonates with the 'Calcutta-insummer' oppressive atmosphere referred to by Ghoshal in his framework. Next, we provide 
some pointers that, drawing from Ghoshal's own blueprint for a people-oriented transformation of the context of organizations, would be conducive to a revitalization of business school culture. Some concluding remarks end the paper.

\section{Ghoshal's 'smell of the place' metaphor}

Ghoshal could hardly be described as a heterodox or 'critical' (in the Leftist sense) figure within the management and organization studies field, so it is all the more telling that his relatively mainstream thinking offers critical leverage with which to interrogate managerialism within UK business school culture. It is Ghoshal's 'springtime theory' that we draw on in our critique. The theory was outlined by Ghoshal in a speech at the World Economic Forum, a video clip of which, under the iconic name 'The smell of the place', is still downloadable from you tube (www.youtube.com/watch?v=UUddgE8rI0E).

Ghoshal's elaboration concerns the 'three Ps' of purpose, process and people, that he argues - organizations are founded upon. It illustrates a people-centered process to achieve the purpose of self-renewal. Ghoshal urges organizations to develop self-renewal abilities by revitalizing employees. Revitalizing employees, in turn, has to do with changing the context and climate that organizations create around them. Ghoshal goes on to propose his 'springtime theory' from this, arguing that approaches to management strongly affect culture: 'the smell of the place'. ${ }^{1}$

This visceral metaphor illustrates the role that organizational contexts play in cultivating holistic effectiveness. It rests on Ghoshal's comparison between his energy level when walking through a forest in Fontainebleau in spring (near INSEAD, where he had worked) and that while visiting his home town of Calcutta in the summer. He 
contrasted the uplifting qualities of life in a springtime forest with the stifling heat and malodorous conditions of an Indian urban setting.

Ghoshal's contention is that many large companies have, metaphorically, 'created downtown Calcutta in summer inside themselves'. We intellectualize a lot in management, says Ghoshal, but if you walk through the door of any organization, within fifteen minutes you get a 'smell of the place', and you can tell straight away whether it is Calcutta or Fontainebleau.

Ghoshal, then, expands the logic of the metaphor by outlining a straightforward conceptual framework for the analysis of culture that seeks to transcend the abstraction. $\mathrm{He}$ argues that the organizational equivalent of the oppressive 'smell' of 'downtown Calcuttain-summer' is associated with the following features: constraint; compliance; control; and contract. Senior management creates strategy but there is a typical top-down approach which generates innumerable constraints (regulations) that limit individual behavior across all levels of the hierarchy. Such constraints are there to tell employees what they can and cannot do. Compliance relates to an elaborate infrastructure of systems (financial, technological, etc.) limiting further individual discretion in decision-making. The unequivocal message being: you have to comply! In Ghoshal's framework control is used to refer to the above-mentioned compliance requirements and, in its most authoritative form, to the power relationship between the employee and the entire management infrastructure. Such a relationship is intrinsically one of dominance, since the control infrastructure exists for the purpose of discipline and surveillance. Finally comes contract, the cornerstone of a formal, binding employer-employee relationship. Inherently asymmetrical in nature, the contract stipulates duties and obligations and it is there to be enforced. 
Ghoshal, then, offers an alternative, people-centered blueprint for creating what he framed as a 'revitalizing' organizational climate. In stridently normative and unitarist rhetoric he calls for stretch, not constraint. Stretch in the sense of creating a shared ambition among employees. The creation of that shared ambition, Ghoshal insists, must go beyond the typical managerial approach in challenging poor performance. Stretch towards a common goal, therefore, that binds people together and provides meaning for everyone's effort. Rather than compliance, this approach relies on cultivation of social norms of selfdiscipline and embedding a pervasive sense of professional identity that drives intrinsic motivation and virtuous employee behavior. ${ }^{2}$ Control is supplanted by support, in terms of accessing resources, employee development, etc. Finally, in place of contract comes trust, effected by spreading a message of openness and transparency and by enacting a process of empowerment.

Even though his work can be roundly positioned as contributing to a mainstream chorus of neoliberal management thinking, Ghoshal, nonetheless, argued against the kind of performativity typically associated with that discourse. He believed, for example, that organizations should stop the obsessive focus on the incremental squeezing out of every morsel of efficiency and every conceivable cost reduction since such a focus can only reinforce the status quo and thus detract attention from new possibilities for 'value creation'. As companies shift emphasis towards value creation, the manager's role should also redefine itself; away from obedience and control to initiative and relationship building.

We should stress at this point that we are by no means apologists for this form of managerial discourse and are certainly not advocating that it should be accepted uncritically. Ghoshal's thinking is, of course, typical of approaches which promulgate a shift from 
'coercive' and 'utilitarian' to 'normative' modes of control in organizations (Etzioni 1961); a development that also prompted robust critiques of the 'culturism' inherent within Cultural Excellence and Total Quality Management framings of organizational relationships (see Willmott 1993). Our point is that, despite being professed (literally) and lauded liberally in business school classrooms, this 'people-centered' discourse has somehow by-passed managerial practice in such schools. Instead what we witness is an increasing fixation with, and intensification of, disciplinary systems of performance management and control.

We would encourage senior university managers and policy makers to step through the door of any UK business school and get a 'smell of the place'. To us, the applicability of Ghoshal's springtime theory to the contemporary organizational context of UK university business schools, is striking. Cunliffe (2009) argues that management studies have been dominated by models that have defined the characteristics of managerial functions, activities, roles and competencies in rationalistic terms. She describes this as the ideology of 'managerialism'. Much has been written (Clarke and Newman 1993; Hoyle and Wallace 2005; Pollitt 1990; Randle and Brady 1997) on how this ideology has taken on a life of its own in government services, education, health care, and other public sector organizations. New managerialism, or New Public Management (NPM) as it is often referred to, has been variously defined but, essentially, is associated with transferring private sector work practices into the public sector. It is characterized by the imposition of a powerful management body with a market orientation and a reformist agenda that overrides professional skills and knowledge, and which, in the HE context, sacrifices educational 
values to rationalist forms of planning as a means of maximizing organizational performance through control.

The objection we raise against managerialism in UK business schools does not concern the typical critiques of the probity of importing private sector practices into the public sector. Following Ghoshal's metaphorical analysis for the purpose of our argument, such a distinction is false. Nor do we question the ontology on which managerialism rests, born, as it is, out of an empiricist mindset that flourishes in political and economic climates requiring evidence of measurable outcomes. Our objection, more simply, is that the hard 'managerialist' management model does not work, irrespective of whether it is adopted within private corporations or the public sector, including university business schools. Many voices call for urgent reform within university business schools, often in response to changes in conditions wrought by the unfettered ascendency of neoliberalism. Accordingly, business schools are seen to face many challenges, including, inter alia: the issue of how to stimulate greater 'student engagement', increasing 'diversity', fast changing technological developments, new curricular demands driven by changes in the world of work and the imperative for ethically and socially responsible organizational practices, increasingly global competitiveness among public, and now private, education providers, and significant cuts in funding regimes. At a time when business schools - pushed and pulled by the forces of neoliberal capitalism - are invited 'to reinvent themselves' (Noorda 2011, 519), and as the rhetoric of the need for business schools to deliver 'distinctiveness' and 'innovation' is stronger than ever (e.g., Alstete 2013), we think it timely to ask what kind of culture is currently being promoted to foster the kind of 'self-renewal' aspired to. 


\section{Theoretical and methodological rationale: the use of 'representative anecdotes'}

It would be legitimate at this point to ask what the sense of 'smell' can really tell us about organizations, their culture and their people and, the extent to which the application of Ghoshal's framework constitutes, in itself, a theoretical contribution. Working in the spirit of the epistemological and methodological tradition of American pragmatism and its prescriptions regarding what counts as research data and theory, we offer a series of 'representative anecdotes' (Burke, 1969, 515) to ironically expose the 'smell of the place' and to advance theoretical reflection. ${ }^{3}$

As recently noted by Rumens and Kelemen $(2013,14)$, for the pragmatists, inquiry must be embodied and embedded in experience if it is to be capable of coping effectively with 'the perennial indeterminancy and contingency with which humans have to struggle in their everyday existence'. John Dewey himself, one of the fathers of the American school of pragmatism, argued that $(1934,22)$ :

The senses are the organs through which the live creature participates directly in the on goings of the world around him. In this participation the varied wonders and splendor of this world are made actual for him in the quality he experiences...

It is our senses, therefore, that allow us to experience the world in one way or another, and failing to account for this experience means escaping into useless theory. In this context, experience also entails our visceral response to the immediate context; it reflects, in Dewey's word, what 'men [sic] do and suffer, what they strive for, believe and 
endure, and also how men act and are acted upon, the ways in which they do suffer, desire and enjoy, see, believe, imagine...' $(1925,8) .{ }^{4}$ This is where our examples and anecdotes come from; our sensory (both metaphorically and physically) perception of lived experience of the UK business school context in which we work, as gathered by recalling personal events and narratives that have been shared with us, by talking and listening to business school academics at work and at conferences, by observing and interpreting behaviors and communications and, through critical reflection, by attempting to connect the parts to the whole, whilst aiming to account for the complex dynamics and multi-layered relationships that operate in the situations and social context studied.

Within the educational milieu, this epistemological orientation towards the theory and practice of interpretation combined with an ontological concern for the meaning of the expressions of lived experience, also resonates with Van Manen's (1977) hermeneuticphenomenological approach to human science; a process of exploring one's understanding of a particular experience by gathering stories from those living it, memories, understandings, and interpreting these in relation to established theoretical predispositions (Ghoshal's springtime theory in our case). Consequently, our narrative bears an affinity to work of bricolage (Denzin and Lincoln, 1994; Duymedjian and Rüling, 2010; Linstead and Grafton-Small, 1990); a collage-like creation of our images and 'smells' of the professional community's experience. Framed within this context, even anecdotes of the communication that normally occurs in staffrooms and refectories become valuable data to be taken into the weaving of the narrative nets that make up the research text. 
We should also note at this point that in strict adherence to ethical guidelines, we deliberately refrain in the paper to attribute and or source some specific examples pertaining to 'voice messages' by management or comments by staff since our intention here is not to implicate, let alone expose, particular individuals (managers or academic staff) but use this anecdotal evidence - itself part of our sensory perception as a mere illustration of the theoretical generalizations subjected to scrutiny and as a foundation - alongside additional material and evidence gathered from relevant literature - for further critical reflection on the current climate of UK business schools. Whilst for some Ghoshal's metaphor may not, in itself, constitute a theoretical contribution, in line with American pragmatism and hermeneutic-phenomenology, we contend that the ensuing conceptualization of the consequences of managerialism for business schools' cultures developed in the paper from the application of Ghoshal's metaphorical generalization, does enhance our knowledge about the 'smell' of the contemporary UK business school, managing and organizing. As Dewey $(1925,240)$ put it, theoretical generalizations are 'not fixed rules ... but instrumentalities for investigation, methods by which the net value of past experiences is rendered available for present scrutiny of new complexities'. On this account, Ghoshal's springtime theory becomes a critical tool to help us think and act differently with respect to the complex reality of contemporary business schools, their management and organizational life, and their wider role in society.

\section{'Bad odors' in UK business schools}


Business schools have been operating as the 'cash-cows' of UK universities for a long time and their financial position seems to have suffered considerably from the further cuts in government funding that followed the recent economic crisis. The subsequent reconfiguration of tuition fees has done little to alleviate ever greater pressures towards the 'bottom line'. Additional rationalizations, squeezed budgets and increased targets now accompany job security fears in schools that, until recently, have only experienced steady growth. The heavy presence of managerialism, moreover, has reinforced a gradual abandonment of the ideal of business schools as research-intensive generators of new knowledge and a relentless gravitation, under the pretences of 'student-centricity' and 'financial sustainability', towards a commercial orientation.

Against this backdrop, the greatest paradox of the managerialist ideology is that whilst it calls for a squeezing out of putative inefficiencies, there has been a proliferation over the past decade of costly procedures implemented in the name of 'the student experience'. This bureaucracy is typified by the bombardment of prescriptive blanket rules on issues such as course guides (templates), teaching formats and associated time slots, group-work models, modes of assessment and moderation, systems of e-marking and efeedback, and even procedures for the uploading of marks (these too, now digitalized and scheduled through ever tighter computerized deadlines). Whilst such a regime, to date, seems to have done little to enhance the quality of the actual student experience ${ }^{5}$, the curriculum (the relevance of which has been questioned from many quarters ranging from professional bodies to accreditation agencies) ${ }^{6}$ or the image of management education and business schools more generally (see Thomas and Cornuel 2012), this overbearing bureaucracy has transformed what was once one of the most rewarding professions into one 
that now records increasing stress levels as a result of a feeling of loss of control in day-today working life. ${ }^{7}$

Indeed, examples of widespread and increasingly violent impositions, ranging from the complete removal of assignment extension decisions from the jurisdiction of course leaders to the more recent 'electronic tagging' of staff, abound.

The latter relates to the prescriptive adoption of the infamous Google 'e-diaries'. First introduced as a means of improving ease of coordination, such a diary system has properties that de facto, make it the perfect instrument of surveillance within the now pervasive 'show us you are working' discourse (see Case, Case, and Catling 2000, for parallels in the UK school sector). 'You' now have to go to yet another meeting because when the e-booking was made 'that time slot in your e-diary showed you weren't teaching'.

As recently noted by Lorenz (2012) in his compelling analysis of the new state of surveillance under neoliberal NPM:

The introduction of permanent control over faculty - which is unprecedented at least in the history of universities in democracies worthy of the name - is nothing other than the introduction of a culture of permanent mistrust. (Lorenz 2012, 609)

From a culturalist perspective, Lewicki, McAllister, and Bies (1998) contend that the attitudes that mistrust produces include fear, skepticism, cynicism, watchfulness and vigilance. Once embedded in social relationships within organizational communities, these dispositions render mistrust an altogether different and hence distinct cultural dimension of 
the human-exchange experience (rather than merely being the low-end of the 'trust scale'). By heavily skewing the healthy 'dynamic tension' between trust and mistrust in favor of the latter, a culture of permanent mistrust, therefore, acts as a source of long-lasting instability in social relationships (ibid).

We invite those readers raising eyebrows to our suggestion of a relentless gravitation towards an Orwellian state of affairs to acknowledge, for example, the evidence of the new wave of police-like surveillance of overseas students undertaken by some UK universities (to fulfill their requirements for Tier 4 license compliance) on behalf of the UK Border Agency. Several UK universities now monitor overseas students' attendance through their wireless internet network, fingerprinting technologies ${ }^{8}$ or, in the name of 'equity', undertake widespread surveillance through a biometric swipe card system to keep tabs on their staff and students. ${ }^{9}$ Amidst these developments ${ }^{10}$ academic staff concerns over employers' interception of their email communications and internet usage are mounting.

Whilst in theory the privacy of email communications ought to be respected by organizations, in practice, privacy concerns can be overridden on the basis of the potential for damage to the institution. Whilst there is yet little evidence to indicate that university staff email communications are being systematically scrutinized, individual academics' suspicions with regard to such infringements have already appeared in the British media. A recent article in Times Higher Education (THE September 5, 2013) reports that some universities now openly assert their right to access staff emails. According to the THE article, City University's website states that the 'misuse' of email can have 'a detrimental effect on other users and potentially the university's public profile'. It is for these reasons, 
that the university 'maintains the right to access user email accounts in the pursuit of an appropriately authorized investigation' (ibid).

Means of electronic surveillance aside, it is quite common nowadays for senior management teams in business schools, particularly in post-1992 universities, to seek overtly to control academic staff, irrespective of their academic experience and seniority. Lorenz (2012) argues that the need for this NPM cadre of managers to resort to increasingly aggressive techniques for exercising power stems from a structural problem: lack of professional authority and academic legitimacy towards the professionals they are supposed to manage in their organizations. As Lorenz $(2012,615)$ writes:

Because they lack professional authority, managers are inclined to treat any lack of cooperation on the shop floor as a threat to their position and as subversion. Those who dare to cast doubt on their decisions can therefore count on pressure, blackmail, divide-and-conquer tactics, and open humiliation.

Even lecture formats are increasingly the province of procedural stipulations, typically requiring PowerPoint slides to be posted in advance of lectures on virtual 'learning' platforms. Bernstein $(1990,181)$ uses the term 'pedagogic devices' for the principles regulating how knowledge is distributed and to what effect. He argues that 'between power and knowledge and knowledge and consciousness is always the pedagogic device' (Bernstein 1990, 181). As one of the authors of this paper experienced himself, in today's environment the 'pedagogic device' itself has become an instrument of 
managerialist power. For example, the mere proposition of turning a lecture into an unconstrained opportunity for engaging students in a Socratic like debate was openly ridiculed by some colleagues, and regarded as heretical by others.

Although any communication technology can be used creatively, there is no question that the institutionalized use of PowerPoint has had profound consequences for classroom communication, the nature of lecturing and expectations of 'best' teaching practices. In the meantime, despite the warnings of critics (for example, Gabriel 2008), the systematic (ab)use of this technology has given life to its most dangerous potential shortcomings. These include the indiscriminate 'parceling of knowledge into bullet points' (Gabriel 2008, 255) and 'the forced linearity of argumentation that limits improvisation, digression and inventiveness' (ibid, 255). Whilst we too have inevitably fallen victim of this now pervasive technology, we are left wondering what the likes of the Sophists or Socrates himself would have made of such a reductionist pedagogic device. What place is there for the development of wisdom (sophia) at a moment in history when students' capacity to pause, reflect and think critically is being seriously challenged by the deepening dependence on the Internet and social media networks?

Another example of compliance to top-down policies whose pedagogical value is questionable and which further diminish professional autonomy and authority, is the compulsory adoption of Turnitin within most UK business schools. This plagiarism detection software hails from a for-profit service provider and is now used by thousands of academic institutions internationally. In the rush to adopt it, university managers appear to have overlooked the way in which this product potentially subverts the academic ethos and constrains students' writing. Indeed, students' ethical concerns (student privacy and student 
property) aside, the imposition of a submission process that forces students to 'turn in' their work digitally and have it subjected to 'plagiarism detection' carries non-trivial implications that force considerable compromises to academic integrity and effective teaching. As noted by Zimmerman (2008), it is the 'educational environment' itself that is most damaged by the compulsory adoption of services like Turnitin. Zimmerman (2008) writes about voices of dissent gathered through articles and blogs about a famous student lawsuit against Turnitin.com, citing the repetition of comments centered on the culture of fear that is created in environments which have forced its implementation. The idea of 'guilty until proven innocent' prevails, she writes, leaving students grappling 'with the uncomfortable assumptions that the use of Turnitin reveals: that students are cheaters who need to be policed'.

This is, indeed, the 'smell of the place' we get when talking to colleagues across the business school sector about the seemingly ineluctable advancement of the frontiers of academic policing. School staff is increasingly being pushed, under duress, to rely on such technology, thus poisoning the classroom atmosphere. The approach effectively compromises the role of academics as educators, forcing them to become the enforcers of a climate of suspicion and mistrust in the classroom. As to the 'value' of the service itself, Zimmerman contends that 'it stands to oversimplify, mislead and undermine our understandings of authorship, text, and reader'.

Although some of our examples may seem trivial, it is also in the enforcement of these new technologies that the NPM 'zombiefication' of academic work (see Gora and Whelan 2010) through 'bureaucratically generated compliance' (ibid) can be found. Moreover, such technologies have long been proven to have the effect of intensifying work 
rather than reducing it (Jacobs 2004) with a resulting increase in the proportion of time spent by academics on administrative tasks in spite of the continuous expansion of dedicated administrative staff within universities employed to service the needs of yet additional layers of management.

Within the culture expressed by managerialist regimes we also witness an amplifier effect with respect to the contractual vehemence with which compliance is enforced, leading to a perverse escalation of energy with which managers exercise control. An open invitation to attend a School workshop helps to illustrate the point. The first School-wide message recognized explicitly the possibility that staff may be on leave or have other commitments and that there is never a date that everyone can make. It also recorded advanced appreciation for making every effort to attend. Just over a week later, a second message reminded staff that unless they were booked on leave, there was an expectation for all academic staff to attend. The message added that there may be, of course, valid reasons why one could not attend, but that these needed to be communicated to the dean's office.

Although generalizations are always unsafe, especially given the different individual styles of deans and the varying stages of development of the managerialist culture within business schools, we would nonetheless claim that the above anecdote epitomizes the identity construction, instrumental interaction and non-collegiate subject positioning that such a culture produces. According to Bernstein's code theory $(2000,79)$, the construction of identities in educational milieux is the result of 'voice message' relations. ${ }^{11}$ 'Voice' refers to who is legitimized to say what to whom in any organizational context; and 'message' is the form of what is said. We view the 'voice message' above as self-evident in giving a sense of the 'smell' of a contemporary UK business school 
environment and the level of (mis)trust between the managerial and academic identities that it expresses.

Whilst manifestations of this regime - typified by initiatives aimed at increasing control of academic staff through bureaucracy, formal authority and coercive power - were once resisted, open dissent has now given way to a form of alienation characterized by deepening estrangement from work, and an increasingly survival-driven focus on the microcosm of immediate, individualized duties. Whereas many academics initially reacted strongly to managerialist assaults and erosion of professional autonomy, this has been replaced by a sense of resignation and powerlessness. Few business school academics are vocal in calling for re-engagement in decision making processes from which they have been excluded, through, for example, collegiate participation (which was a typical response during earlier phases of managerialist encroachment). The degree of disillusionment and demoralization has reached a point whereby a common consequence of 'voice messages' of this sort is an increasing sense of isolation and defeat amongst colleagues. One hears, for example, comments such as, 'I don't care anymore', echoing in the school's corridors, or, even more troubling, 'it is safer to let go and be silent in case of retaliation by management', timorously whispered in the refectory. In short, speaking up at work, let alone engaging in forms of open dissent (formal trade union disputes notwithstanding), is now more than ever perceived as risky in academia. In this cultural climate one is well advised to 'watch one's back’ (Case and Selvester 2002).

Whilst the anecdotal evidence from which we draw above, precludes us from making generalized inferences across the HE sector, we perceive these cases of selfcensorship within business schools to be, in and of themselves, 'malodorous', and quite 
telling in explaining both 'workplace silence' and a 'workplace presence' increasingly bereft of academic consciousness, intellectual self-awareness and professional identity. Indeed, if our experience is anything to go by, withdrawal has become a prevalent personal coping strategy; with colleagues turning up to work purely 'as needs must' to undertake mandatory teaching and administrative duties but otherwise avoiding the office.

In this respect, much appears to have changed since, in the late 1990s, Pritchard and Willmott (1997) engaged in one of the earliest analyses of the changing character of UK universities and of the associated claims (see Parker and Jary 1995) of a transition from 'collegialism' to 'managerialism'. Pritchard and Willmott's (1997) accounts, drawn from discussions with several 'power-holders' in four UK universities, led them to conclude that 'whatever "transition" may be occurring, it is likely to be patchy, extended, and incomplete' (Pritchard and Willmott 1997, 311). Their interviewees included very senior university staff such as vice-chancellor and pro-vice chancellor, high-grade administrative staff, and senior faculty post holders, including deans. Nearly two decades later, our more modest 'ground-level sniffing' suggests that the consequences of this transition have had devastating effects at least as far as organizational culture in UK university business schools is concerned.

Our 'ethereal' perceptions are corroborated by growing evidence of the paradox of an increasingly complicit rather than resistant response to managerialist demands. For example, following interviews with a range of staff in universities but more specifically UK business schools, Clarke, Knights and Jarvis (2012) found that, with few exceptions, 'despite their compliance', staff felt 'considerable disquiet and dissatisfaction' ... 'such that the romantic notion of a "labor of love" where work is an 
end in itself is being stretched to its limits as academics are increasingly subjected to loveless or instrumental demands' (Clarke, Knights and Jarvis 2012, 5).

Gora and Whelan (2010), Ryan (2012), and Walker, Moore, and Whelan (2013) have recently gone as far as using a 'zombie' metaphor to depict the catatonic state many academics have fallen into as a result of successive waves of neoliberal, managerialist reforms to Australian HE. They view the above-mentioned tendency of withdrawal and pervasive sense of helplessness as a zombie-like form of passive resistance and survival in the twilight world of the 'valleys of shadows' that were once known as universities. As Gora and Whelan (2010) write:

\begin{abstract}
Many zombies [...] appear incapable of responding meaningfully to the tyranny of performance indicators, shifting promotion criteria, escalating workload demands and endless audits, evaluations and reviews. The enculturation of such practices has been known to produce catatonia in zombie academics, who often collapse on hearing the word quality, knowing this usually means more hard labor. But try as they may to resist, zombies merely acquiesce to the corporatist line.
\end{abstract}

The deep irony of it all is that managerialist regimes are counterproductive not only in the public and HE sectors but, most pointedly, in the very corporate world in which they originated. Indeed, mainstream management studies literature has purportedly shown, for example, that companies ranked most highly in 'customer satisfaction' ratings and 'financial success' are those that are rated high in 'work environment' and which are seen 
by employees as the 'best companies to work for' (for example, Simon and DeVaro 2006). Political economic critique notwithstanding, our modest plea is that working conditions in business schools might well be improved if not by radical reform then by deans taking account of mainstream messages of this sort and thus perhaps beginning to reverse the obsessive managerialist trajectories.

Organizational culture can be 'smelt' in any corner of an organization but it starts at the top of a hierarchy, where leadership sits. In the words of the Russian proverb: 'the fish rots from the head down'. It is unquestionable that what we are witnessing within UK business schools has historical and political roots, and is happening as part of a deliberate agenda of centralized bureaucratic control by the most senior university administrators. Accordingly, it is business school deans themselves who have a responsibility to act by countering senior management demands at least on how business school objectives are to be achieved as it is deans who are, in primis and ultimately, accountable for the 'smell' of the school environment and its performance.

\section{The 'springtime' of UK business schools}

So, to return to our core 'smell of the place' metaphor: how might we create a 'springtime' climate in UK business schools? And what would such business schools look like? What follows is neither an anarchic manifesto nor a utopian revolutionary agenda; rather we aim tentatively to outline the conditions necessary to cultivate an environment which, drawing from Ghoshal's relatively mainstream blueprint, would be more conducive to self-renewal, improved morale and more effective education in management studies. In short, conditions 
conducive to a 'pleasanter smell'. ${ }^{12}$ To this end, in applying Ghoshal's 'springtime' framework to the HE context, we adopt an unapologetically normative narrative register.

First and foremost, the transformation of the context and culture of UK business schools should entail the removal of the constraints posed by the innumerable ways in which academics' scope for professional judgment is restricted and compromised; particularly insofar as this judgment pertains to pedagogical and androgogical matters.

Directive approaches based on uncompromising compliance, bureaucratic control and electronic surveillance should be replaced by genuinely consensual decision-making processes to inform behavior and consolidate trust-based norms of self-discipline. Such a consensual approach should not be confused with the now common pseudo-consultations that make a pretence of 'involving' academics in issues already decided by senior management. Such exercises are not only costly, they also engender frustration and the intensification of mistrust between academic staff and senior administrators. The consensual approach would, in effect, call for a return to the university culture of an era when 'universities were perceived as communities of scholars researching and teaching together in collegial ways; those running universities were regarded as academic leaders rather than as managers or chief executives' (Deem 1998, 47). This, in turn, would entail 'going back' in order to 'stretch forward' to a more laissez-faire ways of organizing teaching and research founded upon 'the collegiality of academics of equal status working together with minimal hierarchy and maximum trust, and the rather "hands-off" governance practices which were once widespread in that sector' (ibid, 48). These are, after all, the organizational features that Bryman's (2007) research on effective leadership in HE identified as those which academics expect from a supportive school environment: the 
maintenance of academic autonomy, genuine consultation over important decisions, the fostering of collegiality, and fighting the school's corner with senior university management.

On this account, the role of a business school dean is, of course, critical in setting the tone for the kind of leadership that such environment demands. As emphasized by Raelin (1991) a dean's leadership role entails fostering a culture of critical debate, communication, open examination and persuasion rather than one dominated by bureaucratic control. $^{13}$

Such semi-autonomy would be regained as a conditio sine qua non for creating trust, the legitimization of the integrity of competent academic work, and an underpinning for improving professional morale, scholastic commitment and innovation. It is this kind of environment that, prior to the advent of NPM, cultivated the conditions necessary for what Bernstein $(2000,69)$ refers to as 'inner dedication'; a type of commitment and ethical responsibility rooted in a self-disciplining moral structure to which members of a profession align. This does not mean that a climate of high trust could not be complemented by systems of performance checks, 'management by exception', but at least academics would be able to work under the presumption of trust rather than mistrust (as has evolved within managerialist cultures).

\section{Concluding remarks}

Although we would distance ourselves from proposing quick fixes to organizational problems and sweeping advice for restructuring processes that could be taken from any popular management literature picked up at the proverbial airport bookstand, in considering 
how our theoretical reflections advance our conceptual understanding of organizational phenomena, we wish to highlight the paradox that business school academics, alongside business managers themselves, have long been familiar with discourses associated with flat and decentralized organizational structures, staff 'empowerment', 'putting people first' and employee-centricity of all kinds; management practices which purport to, inter alia, boost morale, enhance creativity, innovation and organizational performance. If anything is mainstream in the business school curriculum it is this.

Would-be protagonists and practitioners of managerialism in the HE sector (and in, of all places, business schools) might do well, at least, more properly to reflect in their practices the very lessons that mainstream management thought imparts to the corporate world and to the thousands of students who annually pass through the doors of UK business schools. If widespread resistance to managerialism seems like an increasingly distant prospect in the contemporary UK HE sector, might hope and a perverse form of radicalism be found in promoting mainstream, normative management thinking as a counter to the excesses of managerialism?

\section{References}

Alstete, J.W. 2013. Essential distinctiveness: Strategic alternatives in updating the business core curriculum. Quality Assurance in Education 21, no. 2: 199-210.

Bernstein, B. 1990. Class, codes and control. Volume IV: The structuring of pedagogic discourse. London: Routledge.

Bernstein, B. 2000. Pedagogy, symbolic control and identity. Oxford: Rowman and Littlefield. 
Bryman, A. 2007. Effective leadership in higher education: A literature review. Studies in Higher Education 32, no. 6: 693-710.

Burke, K. 1969. A grammar of motives. London: University of California Press.

Butler, N., and S. Spoelstra. 2012. Your excellency. Organization 19, no. 6: 891-903.

Butler, N., and S. Spoelstra. 2014. The regime of excellence and the erosion of ethos in critical management studies. British Journal of Management 25, no. 3: 538-550.

Case, P., S. Case, and S. Catling. 2000. Please show you're working: A critical assessment of the impact of OFSTED inspection on primary teachers. British Journal of Sociology of Education 21, no. 4: 605-621.

Case, P., and K. Selvester. 2002. Watch your back: Reflections on trust and mistrust in management education. Management Learning 33, no. 2: 231-247.

Clarke, J., and J. Newman. 1993. The right to manage: A second managerial revolution? Cultural Studies 7, no. 3: 427-441.

Clarke, C., D. Knights, and C. Jarvis. 2012. A labour of love? Academics in business schools. Scandinavian Journal of Management 28, no. 1: 5-15.

Collini, S. 2013. Sold out. London Review of Books 35, no. 20: 3-12.

Corbett, J. M. 2006. Scents of identity: Organisation studies and the cultural conundrum of the nose. Cutlure \& Organization 12, no. 3: 221-232. Special issue on sensation and organization.

Cunliffe, A. 2009. A very short, fairly interesting and reasonably cheap book about management. London: Sage.

De Vita, G., and P. Case. 2004. Rethinking the internationalisation agenda in UK higher education. Journal of Further and Higher Education 27, no. 4: 383-398. 
Deem, R. 1998. New managerialism and higher education: The management of performances and cultures in universities in the United Kingdom. International Studies in Sociology of Education 8, no. 1: 47-70.

Denzin, N., and Y. Lincoln. 1994. The handbook of qualitative research in education. Newbury Park, CA: Sage.

Dewey, J. 1925/1929. Experience and Nature. Chicago, IL and London (Revised): Open Court and George Allen \& Unwin.

Dewey, J. 1934. Art as Experience. New York: Minton, Balch.

Duymedjian, R. and C-C. Rüling. 2010. Towards a foundation of bricolage in organization and management theory. Organization Studies 31, no. 2: 133-151.

Etzioni, A. 1961. Comparative analysis of complex organizations. London: CollierMacmillan.

Gabriel, Y. 2008. Against the tyranny of power point: Technology-in-use and technology abuse. Organization Studies 29, no. 2: 255-276.

Gora, J., and A. Whelan. 2010. Invasion of the aca-zombies. The Australian Higher Education Supplement, November 3 [http://www.theaustralian.com.au/highereducation/opinion/invasion-of-aca-zombies/story-e6frgcko$1225946869706 ? \mathrm{nk}=574 \mathrm{c} 98 \mathrm{fd} 25657 \mathrm{~d} 9796694 \mathrm{~b} 020 \mathrm{abb} 8 \mathrm{ffa}]$.

Grey, C., and N.N. Mitev. 2004. Management education: A polemic. In Essential readings in management learning, ed. C. Grey and E. Antonacopoulou, 151-166. London: Sage Publications.

Hartwich, V. 2011. Students under watch: VISA checks and the rise of surveillance in UK universities. A Manifesto Club Report. 
[http://www.manifestoclub.com/files/MC\%20Report students\%20under\%20watch. pdf]

Harvey, D. 2005. A brief history of neoliberalism. Oxford: Oxford University Press.

Hoyle, E., and M. Wallace. 2005. Educational leadership: Ambiguity, professionals and managerialism. London: Sage.

Jacobs, J.A. 2004. The faculty time divide. Sociological Forum 19, no. 1: 3-27.

Lewicki, R.J., D.J. McAllister, and R.J. Bies. 1998. Trust and distrust: New relationships and realities. The Academy of Management Review 23, no. 3: 438-458.

Linstead, S. and R. Grafton-Small. 1990. Organizational bricolage. In B. A. Turner (ed.) Organizational symbolism, 291-309. Berlin: de Gruyter.

Lorenz, C. 2012. If you're so smart, why are you under surveillance? Universities, neoliberalism, and new public management. Critical Inquiry 38, no. 3: 599-629.

Lyotard, J.F. 1984. The postmodern condition: A report on knowledge. Manchester: University of Manchester Press.

Macfarlane, B. 2013. The surveillance of learning: A critical analysis of university attendance policies. Higher Education Quarterly 67, no. 4: 358-373.

Matthews, D. 2014. All together now: Higher education and the cooperative model. Could organising universities in a different way ease institutions' financial woes and bring about greater democracy? Times Higher Education, August 14.

McGettigan, A. 2013. The great university gamble. London: Pluto Press.

Noorda, S. 2011. Future business schools. Journal of Management Development 30, no. 5 : 519-525.

Parker, M. 2014. University, Ltd: Changing a business school. Organization 21, no. 2: 281- 
292.

Parker, M., and D. Jary. 1997. The McUniversity: Organization, management and academic subjectivity. Organization 2, no. 2: 319-338.

Pollitt, C. 1990. Managerialism and the public sector: The Anglo-American experience. Oxford: Blackwell.

Pritchard, C., and H. Willmott. 1997. Just how managed is the McUniversity? Organization Studies 18, no. 2: 287-316.

Radice, H. 2008. Life after death: The Soviet system in British higher education. Journal of Concepts and Philosophy 3, no. 2: 99-120.

Radice, H. 2013. How we got here: UK higher education under neoliberalism. ACME: An International E-Journal for Critical Geographies 12, no. 3: 407-418.

Raelin, J.A. 1991. The clash of cultures: Managers managing professionals. Cambridge, MA: Harvard Business School Press.

Randle, K., and N. Brady. 1997. Further education and the new managerialism. Journal of Further and Higher Education 21, no. 2: 229-239.

Raunig, G. 2013. Factories of knowledge, industries of creativity. Cambridge, MA: MIT Press.

Rumens, N., and M. Kelemen. 2013. American pragmatism and organization studies: Concepts, themes and possibilities. In American pragmatism and organization: Issues and controversies, eds. M. Kelemen and N. Rumens, 3-23. Farnham: Gower

Ryan, S. 2012. Academic zombies: A failure of resistance or a means of survival? Australian Universities' Review 54, no. 2: 3-11.

Simon, H.D., and J. DeVaro. 2006. Do the best companies to work for provide better 
customer satisfaction? Managerial and Decision Economics 27, no. 8: 667-683.

The Economist. 2009. The pedagogy of the privileged. September 24.

The Independent. 2013. Is this really necessary? Universities introduce fingerprinting for international students. November 25 .

Times Higher Education. 2013. Is your university reading your emails? September 5. [http://www.timeshighereducation.co.uk/comment/opinion/is-your-universityreading-your-emails/2007021.article]

Thomas, H., and E. Cornuel. 2012. Guest editorial. Business schools in transition? Issues of impact, legitimacy, capabilities and re-invention. Journal of Management Development 31, no. 4: 329-335.

Van Manen, M. 1977. Linking ways of knowing with ways of being practical. Curriculum Inquiry 6, no. 3: 35-44.

Walker, R., C. Moore, and A. Whelan. 2013. Zombies in the academy: Living death in higher education. Brighton, UK: Intellect Press.

Willmott, H. 1993. Strength is ignorance; slavery is freedom: Managing culture in modern organizations. Journal of Management Studies 30, no. 4: 515-552.

Willmott, H. 1994. Management education: Provocations to a debate. Management Learning 25, no. 1: 105-136.

Zimmerman, T.A. 2008. McLean students file suit against Turnitin.com: Useful tool or instrument of tyranny?

[http://www.ncte.org/cccc/committees/ip/2007developments/mclean].

\section{Notes}


1 We should note that this journal has been pioneering in its exploration of heretofore neglected phenomena relating to 'sensation' in organizations (Culture \& Organization 2006), including the sense of smell (Corbett 2006).

2. One might speculate as to whether Ghoshal had studied and applied some of Foucault's thinking with respect to askesis and identity - developing a sort of Foucauldian 'how to' manual for managers, as it were.

3. According to Burke, the representative anecdote should contain within itself grounds for its own deconstruction or reversal. As he writes, through such dialectical irony the representative anecdote can produce 'a "resultant certainty" of a different quality, necessarily ironic, since it requires that all the sub-certainties be considered as neither true nor false, but contributory' (Burke 1969, 513).

4. The epistemological and methodological implications of this position were underscored by one of the anonymous reviewers who, in response to an earlier version of this paper, observed: 'How we reach such experience is very much at the heart of this paper. Smell (both metaphorically as well as physically) thus provides authentic research data, which does not need to be justified according to the traditional model. For the pragmatists, smell is part of the senses by which we exist in the world and act upon it.'

5. Consider, for example, how such prescriptive procedures aimed at the standardization of the 'education product' fail to cater for the multiplicity of learning styles of our international student populations, and how they run counter to genuinely multicultural and educational processes of teaching and assessment (see 
De Vita and Case 2004).

6. Even The Economist (2009) argued that teaching in business schools lacks a long-range vision and does not emphasize the development of critical thinking.

7 For example, a University and College Union report (released in March 2013), based on a survey of more than 14,000 UK HE staff, found that staff are increasingly stressed by a feeling of loss of autonomy and control over the way they work (http://www.ucu.org.uk/media/pdf/c/f/ucu occstress12 hecontrol.pdf).

8. As adopted, for example, at the universities of Sunderland and Ulster according to a recent article in The Independent (2013).

9. A Manifesto Club report titled 'Students under watch' (Hartwich 2011), exposed Bedfordshire University, Derby University, and Plymouth University as examples of institutions adopting these systems.

10. For a timely contribution on the educational consequences of 'the surveillance of learning', see Macfarlane (2013).

11. Whilst recognizing that culture and identity have very complex relations, it is worth qualifying that Bernstein's interests in 'pedagogic discourse' and what he called 'devices of transmission' focused on how knowledge is relayed through symbolic modalities of practice. He was concerned to examine how these construct different forms of 'consciousness' and thus of 'identity' for those involved in the social and cultural educational mileu (Bernstein 2000). For Bernstein, the construction of particular forms of consciousness has its roots in social relations, and it is the 'pedagogic discourse' (characterized by such 'transmission devices') 
that in addition to constructing knowledge marks the social relationships between educational agents and their specific social identities.

12. Coincidentally, the search for alternative, more democratic models of how to organise universities such as 'cooperativism', has already started to be the subject of media debate. As reported by Matthews (2014), 'Advocates of cooperative universities say that the model would address what they claim is a growing sense of powerlessness among academics and a distrust of senior management' (http://www.timeshighereducation.co.uk/news/all-together-nowhigher-education-and-the-cooperative-model/2015066.article).

13. Even acknowledging the increasing pressures to gain or maintain international accreditations such AACSB and EQUIS (with their inherent instrumentality and wearisome push for standardization), there is nothing intrinsic to the templates of these accreditations that compels deans to steer the implementation of business schools' strategies in a managerialist direction. 